\title{
| Tatuagem e Piereing: quando a moda interfere na saúde pública
}

\author{
| Tattoo and Piereing: when fashion interferes with public health
}

Ana Maria Caldeira Oliveira

Doutoranda em Saúde Pública na Faculdade de Saúde Pública da Universidade de São Paulo.

Pedro Campos Coutinho

Secretaria Municipal de Saúde de Belo Horizonte.

\begin{abstract}
O padrão estético e os modismos sofrem interferências culturais em decorrência de novas percepções e de novos comportamentos, que de forma crescente, surgem em nossa sociedade. Nesse contexto, o estigma que acompanhava as tatuagens e os piercings começa a sofrer transformação, a partir dos anos 1980 quando deixam de ser exclusivos de algumas populações, geralmente marginalizadas, e tornam-se uma opção estética procurada pelas novas gerações ${ }^{1}$. Hoje, o público que faz tatuagens e coloca piercings está presente nas diferentes faixas etárias, níveis de escolaridade eclasses sociais.
\end{abstract}

Pérez ${ }^{1}$ observa (p.189):

"O novo sujeito da tatuagem parece não ter um rosto definido. É múltiplo, diverso, não tem fronteiras de sexo, percorre as diferentes gerações, transita por todas as classes sociais, pertence a distintos níveis educativos, faz diversas atividades, enfim, não possui, como antigamente, um perfil social determinado".

Como consequência da mudança nos hábitos e modismos, novos riscos à saúde são determinados e a vigilância sanitária precisa estar atenta para poder cumprir com sua missão de "proteger e promover a saúde da população" 2 .

A Lei Federal 8.080/903 que regulamenta o Sistema Único de Saúde (SUS) define a vigilância sanitária como um "conjunto de ações capaz de eliminar, diminuir ou prevenir riscos à saúde e de intervir nos problemas sanitários decorrentes do meio ambiente, da produção e 
circulação de bens e da prestação de serviços de interesse da saúde".

Dessa maneira, as práticas de vigilância sanitária se estabelecem com base na noção de risco, ou seja, a possibilidade de ocorrência de dano ou agravoà saúde ${ }^{4}$. Entretanto, deve-se notar que nem sempre é possível a eliminação do risco. Nessas situações, a atuação da vigilância deve ser no sentido de, ao menos, minimizar os riscos à saúde. Como bem observa Costa $^{4}$, além da legislação sanitária e fiscalização do seu cumprimento, a vigilância sanitária pode utilizar-se de outros instrumentos como, por exemplo, o monitoramento da qualidade de produtos e serviços, educação e informação sanitária.

O objetivo deste artigo é relatar a experiência da Vigilância Sanitária da Regional Centro-Sul do município de Belo Horizonte, com uma atuação que vai além da fiscalização aos estabelecimentos de tatuagem e piercing, com ações de caráter educativo junto aos profissionais envolvidos e a conscientização da população sobre os riscos inerentes a essa prática.

Utilizou-se a metodologia qualitativa com adoção da técnica de análise de documentos. Foram analisados os conteúdos das Fichas de Vistoria Fiscal e dos Roteiros de Vistoria Fiscal Sanitária para os Estabelecimentos de Tatuagem e Piercing, baseado na Portaria Municipal 047 de 1999, utilizados nas inspeções realizadas pela Vigilância Sanitária da Regional Centro-Sul aos estabelecimentos de tatuagem e piercing.

Por se tratar de pesquisa realizada com dados secundários, o estudo não foi submetido ao Comitê de Ética em Pesquisa da Secretaria Municipal de Saúde de Belo Horizonte (SMSA). Os dados utilizados foram fornecidos pela Gerência de Vigilância Sanitária da Regional CentroSul.

Foram observados alguns itens do Roteiro de Vistoria Fiscal para os Estabelecimentos de Tatuagem e Piercing, quais sejam: Documentação; Equipamentos para esterilização de artigos; Descarte de resíduos e Controle de infecção.A experiência relatada ocorreu no período compreendido entre os meses de outubro de 2004 até outubro de 2006, sendo dividida em três fases.

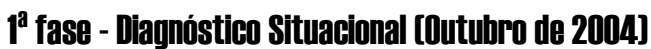

Segundo a Organização Mundial da Saúde - OMS estima-se que existam no Brasil cerca de dois milhões de portadores crônicos da Hepatite B e três milhões da Hepatite $C^{5}$. Essas doenças são consideradas silenciosas, ou em outras palavras, que a maioria das pessoas desconhece sua condição sorológica, agravando ainda mais a cadeia de transmissão. A OMS ressalta que a tatuagem realizada com a utilização de equipamentos não descartáveis e compartilhados constitui forma importante de transmissão das Hepatites Virais 5 .

Nesse cenário, tem início em meados de 2004, a experiência da equipe da Vigilância Sanitária da Regional Centro-Sul do município de Belo Horizonte, Minas Gerais. Essa vigilância sanitária foi provocada pela população, que através de telefonemas, pedia orientações a respeito de 'bons' estúdios para a realização de procedimentos de tatuagem e piercing. Não é à toa que Pérez ${ }^{1}$ destaca como primeiro passo para a realização de uma tatuagem e/ou piercing, a escolha da loja. Segundo a autora, nesse momento, entra em ação a política de "encantamento", que consiste basicamente na procura por três aspectos considerados fundamentais na tatuagem contemporânea: as medidas higiênicas, o trabalho profissional do tatuador e a qualidade artística da tatuagem.

As ações de fiscalização a esses estabelecimentos - estúdios de tatuagem e piercing, regulamentadas pela Portaria Municipal 047 de 19996, eram realizadas naquela época, de forma pontual e por amostragem. As Normas Técnicas para a Fiscalização de Serviços Odontológicos eram utilizadas complementarmente, visando a inspeção dos artigos reprocessados 7 .

Considerando-se o alto risco de contaminação pelas doenças infecto-contagiosas como AIDS, Hepatites $\mathrm{B}$ e $\mathrm{C}$ e a necessidade de responder à população, foram realizadas visitas de inspeção a todos os estabelecimentos de tatuagem e piercing localizados nessa regional/distrito sanitário. Essas inspeções determinaram a necessidade de um relacionamento mais estreito com 
a Associação dos Tatuadores e Pierciers de Minas Gerais (ATAP/MG), uma vez que o conhecimento exigido para a realização das fiscalizações se mostrou mais específico do que aquele importado das Normas Técnicas de Odontologia. Segundo $\operatorname{Costa}^{8}$, as práticas sanitárias exigem a necessidade constante de atualização técnico-científica, em função das novas tecnologias que se expressam na dinâmica do setor produtivo e, que muitas vezes, ainda não foram contempladas com a respectiva produção normativa.

Com o término das inspeções verificou-se uma situação alarmante. As não conformidades constatadas estavam relacionadas à falta de conhecimentos específicos por parte dos profissionais de tatuagem e piercing sobre o processo de esterilização e utilização de medidas de Precaução Padrão, visando o controle de infecções. Cabe esclarecer que medidas de Precaução Padrão são aquelas que devem ser seguidas para todos os pacientes/usuários, independente da suspeita ou não de infecções, entre as elas: higienização das mãos; uso de luvas, óculos, máscara e avental; descarte apropriado de perfuro cortante - seringas e agulhas, sem desconectá-las ou reencapá-las9.

Essa primeira fase foi, portanto, caracterizada pelo diagnóstico situacional. Foi constatado que a prática de tatuagem e piercingestá amplamente difundida, sendo um elemento da moda. A vigilância sanitária, ciente de sua responsabilidade de proteger e promover a saúde da população elaborou um plano de ação, priorizando os profissionais de tatuagem e piercing, bem como os usuários dessa prática.

Foram realizadas visitas de inspeção aos $47(100 \%)$ estabelecimentos de tatuagem e piercing da regional Centro-Sul para verificação das condições higiênico sanitárias.

No momento da vistoria foram realizadas conversas com os profissionais de tatuagem e piercing para conhecer as reais condições, circunstâncias e imprevistos que ocorrem no seu cotidiano.

> Participação de fiscais da vigilância sanitária no Curso Livre de Anatomia do Pavilhão Auricular e Redução de Danos na Aplicação de Body Piercing promovido pela Associação dos Tatuadores e Pierciers de Minas Gerais (ATAP/MG), ara aprender sobre técnicas e processo de trabalho desses profissionais.

> Realização pela Vigilância Sanitária da Regional Centro-Sul de palestra, em evento promovido pela ATAP/MG, III B-H TATTOO 2004, abordando: normas técnicas e rotinas de controle de infecç̃es, adequação do espaço físico e documentação necessária para requerimento do Alvará de Autorização Sanitária.

\section{2 fase-Pronta Aẹ̃a [Fevereiro de 2005]}

Para que fosse executada uma pronta ação em resposta ao problema diagnosticado, era necessário compreender a especificidade desse segmento profissional. Trata-se de uma profissão não regulamentada, com profissionais com baixo grau de instrução e sem formação profissional institucionalizada. $\mathrm{O}$ processo de aprendizagem informal caracteriza esse ofício, que guarda cuidadosamente os seus segredos e truques ${ }^{1}$.

Entretanto, são profissionais que executam, rotineiramente, procedimentos invasivos. Considera-se procedimento invasivo aquele que rompe as barreiras naturais do organismo ou penetra em suas cavidades ${ }^{9}$. Nesse contexto, a viabilidade da ação proposta estava diretamente relacionada à utilização da prática educativa. Ações educativas que promovam a democratização do conhecimento são de fundamental importância para a melhoria dos serviços prestados à população.

Foram feitasinspeção de retorno aos $47(100 \%)$ estabelecimentos de tatuagem e piercing da Regional Centro-Sul;

Realizada pela vigilância sanitária palestra educativa em evento promovido na ATAP/MG, com a apresentação do diagnóstico situacional para os profissionais de tatuagem e piercing; 
Realizada pela vigilância sanitáriapalestra em evento promovido pela ATAP/MG, IV B-H TATTOO 2005, abordando: normas técnicas, rotinas de controle de infecções e documentação necessária para requerimento do Alvará de Autorização Sanitária;

Realizada palestra sobre "Métodos Preventivos de Controle de Infecção em Estabelecimentos de Tatuagem e Piercing" ministrada pela Vigilância Sanitária Centro-Sul;

Elaborado material informativo e educativo sobre os estabelecimentos de tatuagem e piercing, distribuído para a população;

Elaborado material informativo e educativo de afixação obrigatória nos estabelecimentos de tatuagem e piercing;

Ampla divulgação pela mídia do trabalho realizado nos estabelecimentos de tatuagem e piercing com o objetivo de informar a população.

\section{3" fase: Vigilâneia a Estabelecimentos de Tatuagem e Porrelıy[Outubro de 2006]}

A terceira etapa do plano consistiu-se na implementação das ações de monitoramento aos estabelecimentos e a disponibilização de informação para a população sobre as práticas e serviços de tatuagem e piercing.

Foram feitas visitas de inspeção a todos os estabelecimentos de tatuagem e piercing da regional Centro-Sul;

Distribuído material informativo e educativo para a população;

$>$ Reposto material informativo e educativo de afixação obrigatória nos estabelecimentos de tatuagem e piercing;

Realizada "Oficina de Elaboração das Rotinas de Trabalho Para Tatuagem e Piercing" pela Vigilância Sanitária Centro-Sul, com a participação dos profissionais de tatuagem e piercing, com o objetivo de elaborar o procedimento operacional padrão (POPs) para os processos de limpeza e esterilização.

As principais não conformidadesobservadas nas inspeções sanitárias são apresentadas na Tabela 1, bem como a série histórica dessas não conformidades nas três fases do programa.

\begin{tabular}{|c|c|c|c|}
\hline \multicolumn{4}{|l|}{ Principais Resultados } \\
\hline \multicolumn{4}{|l|}{ Documentação } \\
\hline & Out./2004 & Fev./2005 & Out./2006 \\
\hline Obtiveram Alvará Sanitário & $4,2 \%$ & $36,1 \%$ & $40,9 \%$ \\
\hline Não possuíam livro de registro autenticado na Vigilância Sanitária & $82,9 \%$ & $31,9 \%$ & $36,6 \%$ \\
\hline \multicolumn{4}{|l|}{ Equipamentos de Esterilização Utilizados } \\
\hline Estufa & $45,4 \%$ & ---------- & $9,1 \%$ \\
\hline Autoclave & $54,6 \%$ & --------- & $90,9 \%$ \\
\hline \multicolumn{4}{|l|}{ Descarte de Resíduos } \\
\hline Ausência de saco branco leitoso com símbolo de infectante & $44,7 \%$ & $17 \%$ & $2,2 \%$ \\
\hline Descarte inadequado de perfuro cortante & $19,1 \%$ & $2,1 \%$ & $2,2 \%$ \\
\hline Ausência de lixeira com tampa acionada por pedal & $31,9 \%$ & $0 \%$ & $4,5 \%$ \\
\hline \multicolumn{4}{|l|}{ Controle de Infecção } \\
\hline Falha nos procedimentos de esterilização & $59,6 \%$ & $14,9 \%$ & $27,2 \%$ \\
\hline Não utilização de álcool a 70 & $48,9 \%$ & $12,7 \%$ & $2,2 \%$ \\
\hline Não utilização de sabonete líquido & $44,6 \%$ & $17 \%$ & $6,8 \%$ \\
\hline Não utilização de papel toalha descartável & $51 \%$ & $21,3 \%$ & $6,8 \%$ \\
\hline $\begin{array}{l}\text { Não apresentação do comprovante de imunização de Hepatite B dos } \\
\text { profissionais }\end{array}$ & $74,5 \%$ & $23 \%$ & $25 \%$ \\
\hline
\end{tabular}

Fonte: Vigilância Sanitária Centro-Sul de Belo Horizonte. 


\section{Doeumentactão}

Ficou bem caracterizado o total desconhecimento da obrigação legal desses profissionais em requererem o Alvará Sanitário junto àvigilância sanitária, já que 87,23\% deles não o fizeram, sendo que apenas $12,77 \%$ possuíam o citado Alvará Sanitário. E ao não requererem oAlvará Sanitário, não eram fiscalizados por não constarem do cadastro da vigilância sanitária. Esse parâmetro apresentou alteração significativa, uma vez que ao final da $3^{\mathrm{a}}$ fase $41 \%$ dos estabelecimentos possuíam oAlvará Sanitário, tendo cumprido todas as exigências sanitárias necessárias ao funcionamento desses estabelecimentos.

A exigência legal de apresentação e preenchimento do Livro de Registro de Clientes não era cumprida por $82,9 \%$ dos estabelecimentos. Na $3^{\circ}$ fase houve avanço na situação, pois $40,9 \%$ ou menos da metade dos estabelecimentos não possuíam o livro. Entretanto, entre os $59,1 \%$ que possuíam, observou-se uma acomodação por parte de alguns estabelecimentos que possuíam o livro, mas não mantinham seu preenchimento atualizado.

\section{Equipamento de Esterilizạ̧ão}

4,6\% dos estabelecimentos utilizavam autoclave e 45,4\% utilizavam Estufa de Pasteur, popularmente conhecido como estufa. Após a atuação da vigilância, 90,9\% passaram a utilizar a autoclave e apenas $9,1 \%$ continuavam utlizando estufa. Ao conhecer a forma de trabalho dos profissionais de tatuagem e piercing, verificou-se que a utilização do equipamento Estufa dePasteur, seguindo os protocolos prescritos nos manuais do Ministério da Saúde ${ }^{5}$ aquecimento a $160^{\circ} \mathrm{C}$ por 120 minutos ou a $170^{\circ} \mathrm{C}$ por 60 minutos - era incompatível com o tipo de instrumental/artigo utilizado pelos tatuadores.

Entre osinstrumentais estava a agulha montada: uma agulha que precisa ser soldada a uma haste de metal, para que se encaixe na máquina de tatuar, sendo a responsável pela qualidade do desenho. A fragilidade dessas agulhas e a própria solda não permitem que seja respeitado o binômio tempo/temperatura, essencial para a realização do processo de esterilização, já que a alta temperatura danifica a agulha montada e derrete a solda. Nesse sentido, a utilização da autoclave representou grande avanço na adequação do processo de esterilização dosinstrumentais/artigos específicos da prática da tatuagem.

\section{Desearte de Residuos}

Em 44,7\% dos estabelecimentos vistoriados não se utilizava saco branco leitoso com símbolo de infectante para o descarte do resíduo infectante. O descarte inadequado de perfuro cortantes foi constatado em $19,1 \%$ dos estabelecimentos. A ausência de lixeira com tampa a pedal, tanto para o descarte de resíduo infectante como para o descarte de resíduo comum, foi constatada em 31,9\% dos estabelecimentos. A maior adesão ao cumprimento das exigências legais foi observada neste item doRoteiro de Vistoria Fiscal para os Estabelecimentos de Tatuagem e Piercing. No decorrer das fiscalizações mais de $95 \%$ dos estabelecimentos se adequaram as solicitações passando a utilizar saco branco leitoso com símbolo de infectante e lixeira com tampa a pedal, além de proceder corretamente aodescarte dos perfuro cortantes.

\section{Controle de infę̧ãa}

A constatação de que $59,6 \%$ dos estabelecimentos apresentavam falhas nos procedimentos de esterilização soou como um alarme. As conversas com os tatuadores foram fundamentais para a compreensão do processo de trabalho desses profissionais. A revelação da incompatibilidade da utilização do equipamento Estufa de Pasteur com o processo de trabalho foi surpreendente. A fragilidade das agulhas montadas impedia a aplicação adequada do binômio tempo/temperatura, essencial para a realização da esterilização. As joias de piercing, 
exceto as de ouro ou aço cirúrgico, passavam pela estufa no máximo por trinta minutos, pois também sofriam danos na sua estrutura. Verificou-se que o desrespeito ao binômio tempo/temperatura repetia-se com outros artigos como biqueiras, pinças e tesouras. Neste contexto, constatou-se a ineficácia da Estufa de Pasteur como equipamento de esterilização para os serviços detatuagem e piercing.

As principais não conformidades detectadas foram: não esterilização das joias de piercing, utilização de glutaraldeído - método químico - como método de esterilização para as joias de piercing, não utilização de sabonete líquido em $44,6 \%$ dos estabelecimentos e não utilização de papel toalha descartável em $51 \%$ dos estabelecimentos. Todos estes quesitos sofreram melhorias significativas.

Dentro do item, Controle de Infecção (Tabela 1) estão inseridos os subitens: falhas no acondicionamento; falhas nos procedimentos de esterilização e falhas na imunização dos profissionais, que serão discutidos, respectivamente, em acondicionamento dos materiais e saúde do trabalhador.

\section{Acondicionamento dos materiais}

As principais não conformidades detectadas foram a não utilização de embalagens nos artigos/instrumentais esterilizados no equipamento estufa; reutilização de embalagens depapel grau cirúrgico; utilização de estufa para a esterilização dos artigos/instrumentais e posterior empacotamento dos mesmos, em papel grau cirúrgico. Essasnão conformidades eram consequências do desconhecimento, por parte dos profissionais deTatuagem e Piercing, dacorreta forma de acondicionamento e armazenamento dos artigos/instrumentais esterilizados. Com ações educativas sistemáticas como palestras, treinamentos e oficinas foi possível a capacitação desses profissionais, que passaram a realizar os procedimentos adequadamente, com a utilização de invólucro e método de esterilização compatíveis.

\section{Saúde do trabalhador}

Verificou-se que um elevado percentual de estabelecimentos, 74,5\%, não apresentaram o comprovante de imunização anti-VHB de seus profissionais. Nas fases subsequentes este número estabilizou-se em torno de $23-25 \%$, com a conscientização dos profissionais sobre os riscos da atividadeem relação a transmissão da Hepatite B. A utilização de Equipamentos de Proteção Individual (EPI), também aumentou significativamente.

Foram detectadas falhas na limpeza, empacotamento e, principalmente, no processo de esterilização com utilização do equipamentoEstufa de Pasteur. A não utilização de sabonete líquido e toalha descartável comprometiam o processo de lavagem das mãos, que é isoladamente, a ação mais importante para a prevenção e controle de infecções ${ }^{11}$. A adoção de Equipamentos de Proteção Individual (EPI) é obrigatória, porém, dos EPIs necessários, como luvas, máscaras, protetores oculares, avental e gorro, constatou-se que só asluvas e máscaras são de uso rotineiro. A vacinação contra Hepatite B, medida de proteção individual prioritária, também encontra dificuldades de ser cumprida, devido ao esquema de vacinação proposto e a alta rotatividade dos profissionais nos estúdios de tatuagem e piercing. Nesse contexto, são frequentes as falhas nos procedimentos de esterilização e nas medidas de Precaução Padrão, revelando alta probabilidade de ocorrência de infecções pelas Hepatites virais

Com o objetivo de redução imediata nas não conformidades observadas no processo de esterilização, passou-se a exigir, para a liberação do Alvará Sanitário, a apresentação de joias de piercing e agulhas montadas embaladas e esterilizadas individualmente. Essa exigência só é possível de ser realizada com a utilização do equipamento autoclave. O aumento de inadequação na $3^{a}$ fase verificado no quesito "falha nos procedimentos de esterilização" (Tabela 1) deve-se a essa obrigatoriedade.

O descaso verificado no preenchimento do Livro autenticado de Registro de Clientes 
precisa ser revertido. Ressaltamos ser esse livro o único vínculo formal entre a vigilância, o estabelecimento e o usuário do serviço. É através do livro que se verifica a identificação do usuário, o procedimento realizado, local do corpo, idade e a autorização dos pais ou responsável legal, quando menor de 18 anos. Apesar do seu preenchimento incompleto, uma leitura mais detalhada do livro pode revelar informações epidemiológicas de relevância para a Saúde Pública como, por exemplo, o perfil do usuário da prática de tatuagem e piercing.

Os tatuadores e pierciers, em sua maioria, possuem baixo grau de instrução - $2^{\circ}$ grau incompleto - e sua atividade encontra-se ainda em processo de profissionalização. Dessa maneira, esses profissionais não tem a quem recorrer para a produção ou transmissão do conhecimento técnico específico, necessário a realização de sua arte. Nesse sentido, em respeito ao princípio da equidade, a vigilância sanitária propôs e executou ações educativas sistemáticas que promoveram a capacitação dos profissionais envolvidos, tendo como consequência a melhoria dos serviços prestados à população.

O relato de experiência da Vigilância Sanitária da Regional Centro-Sul demonstrou a importância, não só da realização de sua principal atividade,afiscalização, mas também, de ações informativas e educativas. Avigilância sanitária, bem como o trabalhador de vigilância sanitária, precisou romper com a lógica tradicional de ações e serviços devigilância sanitária, buscando complementar seu trabalho com atividades comunicativas e pedagógicas.

Esse esforço resultou na democratização do conhecimento, e por consequência, na conscientização dos prestadores de serviços e da população. Envolver a população através da divulgação da informação significa investir em uma população socialmente responsável.O resultado é a melhoria dos serviços prestados e, também, uma população que ao conhecer e reconhecer os riscos torna-se mais exigente e crítica. Assim, a Vigilância Sanitária da Regional Centro-Sul do município de Belo Horizonte efetivou-se como instrumento de cidadania transformador da realidade social.

\section{Referências}

1. Pérez AL. A identidade à flor da pele: etnografia da prática da tatuagem na contemporaneidade. Mana. 2006;12:179206.

2. Agência Nacional de Vigilância Sanitária (ANVISA) [homepage na internet]. Brasilia. [acessado 2014 Mar 27]; Disponível em: http://portal.anvisa.gov.br/wps/portal/anvisa/anvisa/agencia

3. Brasil. Lei $n^{\circ} 8.080$, de 19 de setembro de 1990. Dispõe sobre as condições para a promoção, proteção e recuperação da saúde, a organização e o funcionamento dos serviços correspondentes e dá outras providências. Diário Oficial da União. 20 de set 1990a;Seção 1:018055.

4. Costa EA. Vigilância Sanitária e Proteção da Saúde. In: Direito Sanitário e Saúde Pública. Volume I. Coletânea de Textos. Brasília: Ministério da Saúde; 2003. p.189-217.

5. Ministério da Saúde, Secretaria de Vigilância em Saúde. Departamento de Vigilância Epidemiológica. Manual de aconselhamento em hepatites virais. Ministério da Saúde, Secretaria de Vigilância em Saúde. Departamento de Vigilância Epidemiológica. Brasília: Ministério da Saúde; 2005.

6. Belo Horizonte. Código Sanitário do Município de Belo Horizonte. Portaria SMSA/SUS-BH No 047 de 30 de agosto de 1999. Dispõe sobre a Fiscalização e Vigilância Sanitária do serviço de tatuagens, disciplina os locais apropriados para este fim, adota medidas de proteção sanitária e dá outras providências.

7. Ministério da Saúde, Secretaria de Políticas de Saúde, Coordenação Nacional de DST e AIDS. Controle de infecções e prática odontológica em tempos de AIDS: manual de condutas. Brasília: Ministério da Saúde; 2000.

8. Costa EA. O trabalhador de vigilância sanitária e a construção de uma nova vigilância: fiscal ou profissional de saúde? In: Costa EA, organizadora. Vigilância sanitária: desvendando o enigma. Salvador: Edufba; 2008. p. 77-90.

9. Agência Nacional de Vigilância Sanitária (ANVISA) [homepage na internet]. Brasilia. [acessado 2014 Mar 27]; Disponível emhttp://www.anvisa.gov.br/servicosaude/controle/precaucoes_a3.pdf

10. 10.Yamaushi NI, Munhoz CHF, Ferreira AMTGB. Procedimentos Invasivos. In: Fernandes AT, organizador. Infecção hospitalar e suas interfaces na área da saúde. São Paulo: Atheneu; 2000. p. 957-97.

11. Ministério da Saúde.Portaria $n^{\circ}$ 2616, de 12 maio de 1998.Programa de Controle de Infecções Hospitalares.[acessado 2014 Mar 27]; Disponível em http://bvsms.saude.gov.br/bvs/saudelegis/gm/1998/prt2616_12_05_1998.html 